\title{
Early stroke risk and ABCD2 score performance in tissue- vs time-defined TIA
}

\section{A multicenter study}

(6)

M.F. Giles, DPhil G.W. Albers, MD P. Amarenco, MD E.M. Arsava, MD A.W. Asimos, MD H. Ay, MD

D. Calvet, $\mathrm{MD}$

S.B. Coutts, MD

B.L. Cucchiara, MD

A.M. Demchuk, MD

S.C. Johnston, MD

P.J. Kelly, MD

A.S. Kim, MD

J. Labreuche, BS

P.C. Lavallee, MD

J.-L. Mas, MD

A. Merwick, MB

J.M. Olivot, MD

F. Purroy, MD

W.D. Rosamond, PhD

R. Sciolla, MD

P.M. Rothwell, PhD

Address correspondence and reprint requests to Matthew F. Giles, Stroke Prevention Research Unit, NIHR Biomedical Research Centre, Oxford University Department of Clinical Neurology, Level 6, West Wing, John Radcliffe Hospital, Oxford OX3 9DU, UK matthew.giles@clneuro.ox.ac.uk

Editorial, page 1214

Supplemental data at www.neurology.org

Supplemental Data
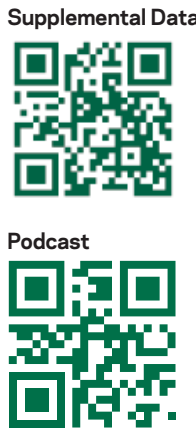

\section{ABSTRACT}

Objectives: Stroke risk immediately after TIA defined by time-based criteria is high, and prognostic scores (ABCD2 and ABCD3-I) have been developed to assist management. The American Stroke Association has proposed changing the criteria for the distinction between TIA and stroke from time-based to tissue-based. Research using these definitions is lacking. In a multicenter observational cohort study, we have investigated prognosis and performance of the ABCD2 score in TIA, subcategorized as tissue-positive or tissue-negative on diffusion-weighted imaging (DWI) or CT imaging according to the newly proposed criteria.

Methods: Twelve centers provided data on ABCD2 scores, DWI or CT brain imaging, and follow-up in cohorts of patients with TIA diagnosed by time-based criteria. Stroke rates at 7 and 90 days were studied in relation to tissue-positive or tissue-negative subcategorization, according to the presence or absence of brain infarction. The predictive power of the ABCD2 score was determined using area under receiver operator characteristic curve (AUC) analyses.

Results: A total of 4,574 patients were included. Among DWI patients ( $\mathrm{n}=3,206$ ), recurrent stroke rates at 7 days were $7.1 \%$ (95\% confidence interval 5.5-9.1) after tissue-positive and $0.4 \%(0.2-0.7)$ after tissue-negative events ( $p$ diff < 0.0001). Corresponding rates in CT-imaged patients were 12.8\% (9.3-17.4) and 3.0\% (2.0-4.2), respectively (p diff < 0.0001). The ABCD2 score had predictive value in tissue-positive and tissue-negative events (AUC = 0.68 [95\% confidence interval 0.63-0.73] and 0.73 [0.67-0.80], respectively; $p$ sig $<0.0001$ for both results, $p$ diff $=0.17$ ). Tissue-positive events with low ABCD2 scores and tissue-negative events with high ABCD2 scores had similar stroke risks, especially after a 90-day follow-up.

Conclusions: Our findings support the concept of a tissue-based definition of TIA and stroke, at least on prognostic grounds. Neurology ${ }^{\circledR} 2011 ; 77: 1222-1228$

\section{GLOSSARY}

$\mathbf{A C S}=$ acute coronary syndrome; $\mathbf{A S A}=$ American Stroke Association; $\mathbf{A U C}=$ area under the receiver operator characteristic curve; $\mathbf{C l}$ = confidence interval; $\mathbf{D W I}=$ diffusion-weighted MRI; ED = emergency department.

The risk of recurrent stroke immediately after TIA is high. ${ }^{1,2}$ The ABCD2 score is a prognostic score for risk stratification in the acute phase, ${ }^{3}$ and its use has been recommended in national guidelines. ${ }^{4-6}$ Recently, the ABCD2 score had been modified to incorporate brain and vascular imaging to further improve prognostication (ABCD3-I). ${ }^{7,8}$

These prognostic studies were conducted in patients with TIA defined by time-based criteria, recommended by the World Health Organization. 9,10 The American Stroke Association (ASA) has recently proposed revising the definitions from time-based to tissue-based criteria, ${ }^{11}$

\footnotetext{
From the Stroke Prevention Research Unit (M.F.G., P.M.R.), NIHR Biomedical Research Centre, John Radcliffe Hospital, Oxford, UK; Department of Neurology and Neurological Sciences (G.W.A., J.M.O.), Stanford Stroke Center, Palo Alto, CA; Department of Neurology and Stroke Centre (P.A., J.L., P.C.L.), Bichat-Claude Bernard University Hospital, Paris, France; Departments of Neurology and Radiology (E.M.A., H.A.), Massachusetts General Hospital, Boston; Department of Emergency Medicine (A.W.A.), Carolinas Medical Center, Charlotte, NC; Department of Neurology (D.C., J.-L.M.), Centre Hospitalier Sainte-Anne, Paris, France; Departments of Clinical Neurosciences and Radiology (S.B.C., A.M.D.), Seaman Family Centre, University of Calgary, Calgary, Canada; Department of Neurology (B.L.C.), University of Pennsylvania Medical Center, Philadelphia; Department of Neurology (S.C.J., A.S.K.), University of California, San Francisco, San Francisco; Neurovascular Clinical Science Unit (P.J.K., A.M.), Mater University Hospital, Dublin, Ireland; Department of Neurology (F.P.), University of Lleida, Lleida, Spain; Neurology Department (R.S.), University of Turin, Turin, Italy; and Department of Epidemiology (W.D.R.), University of North Carolina School of Public Health, Chapel Hill.

Study funding: P.M.R. has an NIHR Senior Fellowship.

Disclosure: Author disclosures are provided at the end of the article.
} 


\begin{tabular}{|c|c|c|c|c|c|}
\hline \multirow{3}{*}{$\begin{array}{l}\text { Table } 1 \\
\text { Study }\end{array}$} & \multicolumn{5}{|c|}{$\begin{array}{l}\text { Total numbers of participants, numbers with infarction on brain } \\
\text { scanning, and stroke outcomes at } 7 \text { and } 90 \text { days }\end{array}$} \\
\hline & \multirow[b]{2}{*}{$\begin{array}{l}\text { Imaging } \\
\text { modality }\end{array}$} & \multirow[b]{2}{*}{ No. } & \multirow[b]{2}{*}{ Infarction } & \multicolumn{2}{|l|}{ Strokes } \\
\hline & & & & $7 \mathrm{~d}, \mathrm{n}(\%)$ & $90 \mathrm{~d}, \mathrm{n}(\%)$ \\
\hline California $^{20}$ & CT & 322 & 80 & $19(5.9)$ & 35 (10.9) \\
\hline OXVASC $^{17}$ & $\mathrm{CT}$ & 227 & 79 & 28 (12.3) & 45 (19.8) \\
\hline \multirow[t]{2}{*}{ Cucchiara et al..$^{24}$} & DWI & 96 & 22 & $4(2.4)$ & $5(3.0)$ \\
\hline & CT & 71 & 30 & & \\
\hline \multirow[t]{2}{*}{ Lavallee et al. ${ }^{25}$} & DWI & 880 & 134 & $5(0.5)$ & $17(1.6)$ \\
\hline & $\mathrm{CT}$ & 204 & 33 & & \\
\hline SINPAC $^{19}$ & $\mathrm{CT}$ & 274 & 53 & $10(3.6)$ & $15(5.4)^{a}$ \\
\hline Calgary ${ }^{21}$ & DWI & 111 & 41 & $4(3.6)$ & $6(5.4)$ \\
\hline Calvet et al. ${ }^{26}$ & DWI & 339 & 136 & $5(1.5)$ & $10(2.9)$ \\
\hline Ay et al. ${ }^{28}$ & DWI & 586 & 200 & $28(4.8)$ & NA \\
\hline Purroy et al. ${ }^{22}$ & DWI & 204 & 95 & $3(1.5)$ & $9(4.4)$ \\
\hline Stanford ${ }^{28}$ & DWI & 99 & 15 & $1(1.0)$ & $1^{\mathrm{b}}$ \\
\hline \multirow[t]{2}{*}{ NDSS ${ }^{18}$} & DWI & 125 & 30 & $2(0.9)$ & $10(4.7)$ \\
\hline & $\mathrm{CT}$ & 88 & 37 & & \\
\hline \multirow[t]{2}{*}{ Asimos et al. ${ }^{23}$} & DWI & 766 & 211 & $36(3.8)$ & $38(4.0)$ \\
\hline & CT & 182 & 15 & & \\
\hline
\end{tabular}

Abbreviations: DWI = diffusion-weighted MRI; NA = not available; NDSS = North Dublin Stroke Study; OXVASC = Oxford Vascular Study; SINPAC = Societá Inter-regionale Piemonte-Aosta Cerebrovasculopatie.

${ }^{\text {a }}$ Follow-up available only to 30 days.

b Follow-up to 90 days available for 85 subjects.

advocating that stroke and TIA be distinguished by the presence or absence of brain infarction identified on diffusion-weighted MRI (DWI). ${ }^{12}$

Infarction on DWI has been found to be associated with a high early stroke risk in a number of studies, ${ }^{13-15}$ but methodology has been inconsistent and sample sizes small. Although CT is an inferior imaging modality in TIA, its use continues where DWI is not available or contraindicated. The association between brain infarction on CT and early stroke risk after TIA is less well studied. The performance of prognostic tools has not been studied in TIA and stroke defined by tissuebased criteria.

We have therefore conducted a large, multicenter study of the early risk of recurrent stroke after TIA, subcategorized as tissuepositive or tissue-negative on either DWI or CT according to the newly proposed criteria. ${ }^{11}$ We have tested the hypothesis that the $\mathrm{ABCD} 2$ score is prognostic when applied to these groups.
METHODS This is an international, multicenter collaborative study, the methods of which have been described previously. ${ }^{7}$ In brief, 12 independent research centers were identified from a systematic review and electronic literature search as collecting sufficiently detailed prospective data on $\mathrm{ABCD} 2$ score, brain imaging results, and prognosis in cohorts of patients with TIA. ${ }^{16}$

Centers submitted previously unpublished tabular data on cohorts of patients with TIA (defined by time-based criteria), categorized by $\mathrm{ABCD} 2$ score and the presence or absence of brain infarction, describing the outcome of recurrent stroke at 7 and 90 days. Patients were eligible if they gave written, informed consent to participation in the study, had brain imaging in the acute phase by either MRI or CT and follow-up to at least 7 days. Patients with minor stroke according to time-based criteria or alternative, non-neurovascular diagnoses were excluded. Recurrent stroke was defined as a new neurologic deficit of vascular origin which lasted more than 24 hours or led to death and occurred after complete resolution of the inception TIA. Those who received imaging only after a recurrent stroke and not in the interval between inception TIA and recurrent stroke were excluded.

ABCD2 scores were calculated by local investigators after face-to-face evaluation. Follow-up was by face-to-face or telephone review or examination of clinical records. Brain infarction was determined by either a dedicated study neurologist or radiologist or from routine reports in individual centers. In centers where patients were imaged with both MRI and CT only MRI results were recorded to avoid double counting of individuals. For patients imaged with DWI, any acute infarction was recorded, irrespective of whether it was appropriate to the presenting symptoms. For patients imaged with CT, any infarction was recorded, regardless of age, given the unreliability of distinguishing between acute and old infarction. Changes attributed to leukoaraiosis were not recorded.

To study outcomes and predictors according to tissuedefined criteria, subjects with time-defined TIA were subcategorized as tissue positive or tissue-negative according to the presence or absence of brain infarction as defined above. Tissuepositive TIA therefore corresponded to stroke with rapid and complete symptomatic recovery according to the ASA definition and tissue-negative TIA corresponded to TIA.

Statistical analysis. To examine the predictive power of the $\mathrm{ABCD} 2$ score, discrimination was studied using the area under the receiver operator characteristic curve (AUC) with $95 \%$ confidence interval (CI) using standard methods. Ideal discrimination produces an AUC of 1.0, and discrimination that is no better than chance produces an AUC of 0.5. Analyses were done with SPSS version 15.0 (SPSS, Inc., Chicago, IL).

Standard protocol approvals, registrations, and patient consent. All collaborating centers received approval from local ethical standards committees for the study, and written informed consent for participation in the study was obtained from all subjects.

RESULTS Table e- 1 on the Neurology ${ }^{\circledR}$ Web site at www.neurology.org describes the methods used in each of the 12 centers. Two studies were populationbased, ${ }^{17,18} 5$ were from emergency departments (EDs), ${ }^{19-23}$ and 5 were from specialist neurovascular units. ${ }^{24-28}$ Five studies used DWI only, ${ }^{21,22,26-28} 3$ studies used CT imaging only, ${ }^{17,19,20}$ and 4 used a combination of the 2 modalities. ${ }^{18,23-25}$ These last 4 


\begin{tabular}{|c|c|c|c|c|c|c|c|c|c|c|c|c|c|}
\hline \multirow{4}{*}{\multicolumn{2}{|c|}{$\begin{array}{l}\text { Table } 2 \text { Num } \\
\text { for C }\end{array}$}} & \multicolumn{12}{|c|}{$\begin{array}{l}\text { mber of strokes, number of patients, and stroke risk at } 7 \text { and } 90 \text { days by ABCD2 score in patients with and without infarction } \\
\text { CT and DWI cohorts combined and DWI cohorts only }\end{array}$} \\
\hline & & \multicolumn{6}{|l|}{$7 d$} & \multicolumn{6}{|l|}{$90 \mathrm{~d}$} \\
\hline & & \multicolumn{3}{|c|}{ With infarction } & \multicolumn{3}{|c|}{ Without infarction } & \multicolumn{3}{|c|}{ With infarction } & \multicolumn{3}{|c|}{ Without infarction } \\
\hline & & Stroke & No. & $\begin{array}{l}\text { \% Risk } \\
\text { (95\% Cl) }\end{array}$ & Stroke & No. & $\begin{array}{l}\text { \% Risk } \\
\text { (95\% Cl) }\end{array}$ & Stroke & No. & $\begin{array}{l}\text { \% Risk } \\
\text { (95\% Cl) }\end{array}$ & Stroke & No. & $\begin{array}{l}\text { \% Risk } \\
\text { (95\% Cl) }\end{array}$ \\
\hline \multicolumn{14}{|c|}{$\begin{array}{l}\text { All CT and MRI } \\
\text { cohorts combined }\end{array}$} \\
\hline$\leq 1$ & & 0 & 27 & $0.0(0.0-0.0)$ & 0 & 272 & $0.0(0.0-0.0)$ & 0 & 22 & $0.0(0.0-0.0)$ & 2 & 243 & $0.8(0.1-3.0)$ \\
\hline 2 & & 2 & 95 & $2.1(0.3-7.6)$ & 0 & 447 & $0.0(0.0-0.0)$ & 3 & 73 & $4.1(0.8-12)$ & 1 & 379 & $0.3(0.0-1.5)$ \\
\hline 3 & & 5 & 177 & $2.8(0.9-6.6)$ & 3 & 647 & $0.5(0.1-1.4)$ & 6 & 135 & $4.4(1.6-9.7)$ & 9 & 518 & $1.7(0.8-3.3)$ \\
\hline 4 & & 15 & 310 & $4.8(2.7-8)$ & 10 & 855 & $1.2(0.6-2.2)$ & 20 & 248 & $8.1(4.9-12.5)$ & 11 & 697 & $1.6(0.8-2.8)$ \\
\hline 5 & & 42 & 329 & $12.8(9.2-17.3)$ & 12 & 682 & $1.8(0.9-3.1)$ & 45 & 265 & $17.0(12.2 .7)$ & 17 & 528 & $3.2(1.9-5.2)$ \\
\hline$\geq 6$ & & 41 & 273 & $15.0(10.8-20.4)$ & 15 & 460 & $3.3(1.8-5.4)$ & 41 & 215 & 19.1 (13.5.9) & 21 & 377 & $5.6(3.4-8.5)$ \\
\hline Total & & 105 & 1,211 & $8.7(7.1-10.5)$ & 40 & 3,363 & $1.2(0.8-1.6)$ & 115 & 958 & $12(9.9-14.4)$ & 61 & 2,742 & $2.2(1.7-2.9)$ \\
\hline \multicolumn{14}{|c|}{ MRI cohorts only } \\
\hline$\leq 1$ & & 0 & 20 & $0.0(0.0-0.0)$ & 0 & 225 & $0.0(0.0-0.0)$ & 0 & 15 & $0.0(0.0-0.0)$ & 1 & 204 & $0.5(0.0-2.7)$ \\
\hline 2 & & 1 & 68 & $1.5(0.0-8.2)$ & 0 & 329 & $0.0(0.0-0.0)$ & 0 & 51 & $0.0(0.0-0.0)$ & 0 & 283 & $0.0(0.0-0.0)$ \\
\hline 3 & & 3 & 135 & $2.2(0.5-6.5)$ & 1 & 469 & $0.2(0.0-1.2)$ & 1 & 98 & $1.0(0.0-5.7)$ & 5 & 376 & $1.3(0.4-3.1)$ \\
\hline 4 & & 12 & 228 & $5.3(2.7-9.2)$ & 4 & 577 & 0.7 (0.2-1.8) & 12 & 184 & $6.5(3.4-11.4)$ & 4 & 485 & $0.8(0.2-2.1)$ \\
\hline 5 & & 23 & 241 & 9.5 (6.0-14.3) & 3 & 454 & $0.7(0.1-1.9)$ & 20 & 192 & $10.4(6.4-16.1)$ & 7 & 359 & $1.9(0.8-4.0)$ \\
\hline$\geq 6$ & & 24 & 192 & $12.5(8.0-18.6)$ & 1 & 268 & $0.4(0.0-2.1)$ & 20 & 144 & $13.9(8.5-21.5)$ & 2 & 215 & $0.9(0.1-3.4)$ \\
\hline Total & & 63 & 884 & $7.1(5.5-9.1)$ & 9 & 2,322 & $0.4(0.2-0.7)$ & 53 & 684 & $7.7(5.8-10.1)$ & 19 & 1,922 & $1.0(0.6-1.5)$ \\
\hline
\end{tabular}

Abbreviations: $\mathrm{Cl}$ = confidence interval; DWI = diffusion-weighted MRI.

studies contributed 2 cohorts each, 1 DWI and 1 CT. In 1 study, ${ }^{19}$ the ABCD score only was recorded, and this was substituted for the ABCD2 score in relevant analyses. In 3 cohorts, follow-up data were either incomplete or unavailable beyond 7 days. ${ }^{19,27,28}$

Table 1 shows the rate of brain infarction observed and the risk of recurrent stroke at 7 and 90 days. A total of 4,574 patients were included in the study. Among 3,206 imaged with DWI, 884 (27.6\%) had acute brain infarction and among 1,368 imaged with CT, 327 (23.9\%) had acute or old infarction. Rates of infarction varied considerably between studies $\left(15.2 \%^{28}-46.6 \%{ }^{22}\right.$ in DWI cohorts, and $8.2 \%{ }^{23}-42.0 \%{ }^{18}$ in CT cohorts). Of those imaged with DWI and CT, $72(2.2 \%$; $95 \%$ CI $1.8-$ 2.8 ) and 73 (5.3\%; 95\% CI 4.2-6.7), respectively, had a recurrent stroke at 7 days. Rates of recurrent stroke differed between cohorts, with higher rates observed in population-based and ED-based studies and lower rates observed in studies based in neurovascular units.

Table 2 shows the rate of recurrent stroke at 7 and 90 days categorized by $\mathrm{ABCD} 2$ scores and by the presence or absence of infarction for DWI alone cohorts and for CT and DWI cohorts combined. For those imaged with DWI, pooled rates of recurrent stroke at 7 days were $7.1 \%$ (95\% CI 5.5-9.1) in those with tissue-positive events, compared with $0.4 \%(0.2-0.7)$ in those with tissue-negative events ( $p$ diff $<0.0001$ ). For those imaged with CT, corresponding rates were $12.8 \%(9.3-17.4)$ and $3.0 \%$ (2.0-4.2), respectively ( $p$ diff $<0.0001$ ).

Patients with infarction had higher ABCD2 scores than those without $(p<0.0001$, MannWhitney $U$ test), as shown in the figure. However, the $\mathrm{ABCD} 2$ score was predictive of recurrent stroke at 7 days in those with and without infarction. AUCs for the prediction of stroke at 7 days by the ABCD2 score for tissue-positive and tissue-negative events were 0.68 (95\% CI $0.63-0.73)$ and $0.73(0.67-$ 0.80 ), respectively ( $p$ sig $<0.0001$ for both results, $p$ diff $=0.17$ ). For those imaged with DWI, corresponding AUCs were $0.67(0.61-0.73)$ and 0.66 $(0.54-0.78)$ ( $p$ sig $<0.0001$ for both results) and for those imaged with CT, AUCs were 0.69 (0.62$0.76)$ and $0.72(0.65-0.80)(p$ sig $<0.0001$ for both results). AUCs for prediction of recurrent stroke at 90 days were $0.66(0.61-0.71)$ and 0.69 (0.62$0.76)$, respectively, for tissue-positive and tissuenegative events overall ( $p$ sig $<0.0001$ for both results), $0.69(0.63-0.75, p<0.0001)$ and 0.61 $(0.50-0.72, p=0.1)$ for those imaged by DWI, and 
Figure Pooled analysis of association between ABCD2 score and presence of infarction on diffusion-weighted imaging (DWI) or CT brain imaging

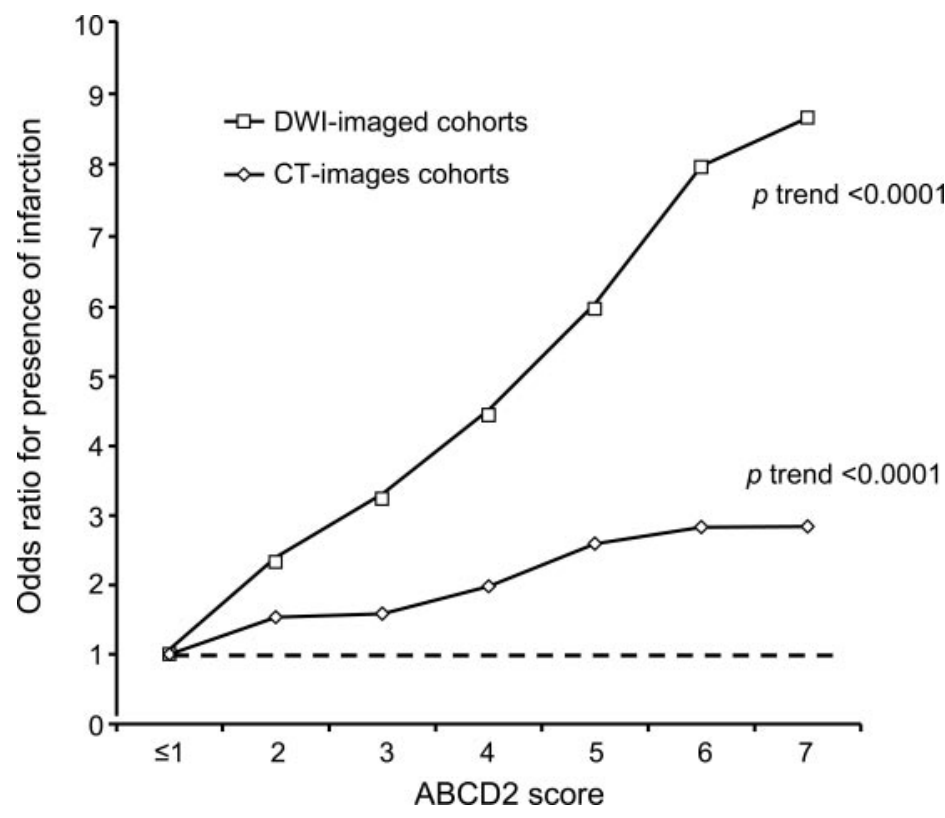

Odds ratios are relative to an $A B C D 2$ score of $\leq 1$.

$0.64(0.56-0.71, p=0.001)$ and $0.69(0.61-0.77$, $p<0.0001)$ for those imaged with CT.

Comparable or even overlapping rates of recurrent stroke were observed in tissue-positive and tissue-negative events, depending on $\mathrm{ABCD} 2$ score; for instance, among DWI patients, the 90-day stroke rate was $0.6 \%$ in tissue-positive events with $\mathrm{ABCD} 2$ $\leq 3$ compared with $1.2 \%$ in tissue-negative events with $\mathrm{ABCD} 2>3$. Table 3 shows pooled stroke out-

\begin{tabular}{|c|c|c|c|}
\hline \multirow[t]{2}{*}{ Table 3} & \multicolumn{3}{|c|}{$\begin{array}{l}\text { Numbers of strokes and numbers of patients at } 7 \text { days by ABCD } 2 \\
\text { score cutpoints of } 0-3,4-5 \text {, and } 6-7 \text { in patients with and } \\
\text { without infarction for cohorts pooled according to imaging } \\
\text { modality and overall }\end{array}$} \\
\hline & & No. of patients (\% stroke $r$ & $\% \mathrm{Cl})$ \\
\hline \multicolumn{2}{|c|}{ ABCD2 score cutpoint } & With infarction & Without infarction \\
\hline \multicolumn{4}{|l|}{ DWI } \\
\hline \multicolumn{2}{|l|}{$0-3$} & $4 / 223(1.8,0.5-4.6)$ & $1 / 1,023(0.1,0.0-0.5)$ \\
\hline \multicolumn{2}{|l|}{$4-5$} & $35 / 469(7.5,5.2-10.4)$ & $7 / 1,031(0.7,0.3-1.4)$ \\
\hline \multicolumn{2}{|l|}{$6-7$} & $24 / 192(12.5,8.0-18.6)$ & $1 / 268(0.4,0.0-2.1)$ \\
\hline \multicolumn{4}{|l|}{ Ст } \\
\hline \multicolumn{2}{|l|}{$0-3$} & $3 / 76(3.9,0.8-11.5)$ & $3 / 343(0.9,0.2-2.6)$ \\
\hline \multicolumn{2}{|l|}{$4-5$} & $22 / 170(12.9,8.1-19.6)$ & $15 / 506(3.0,1.7-4.9)$ \\
\hline \multicolumn{2}{|l|}{$6-7$} & 17/81 (21.0, 12.2-33.6) & $14 / 192(7.3,4-12.2)$ \\
\hline \multicolumn{4}{|l|}{ All } \\
\hline \multicolumn{2}{|l|}{$0-3$} & $7 / 299(2.3,0.9-4.8)$ & $3 / 1,366(0.2,0.0-0.6)$ \\
\hline \multicolumn{2}{|l|}{$4-5$} & $57 / 639(8.9,6.8-11.6)$ & $22 / 1,537(1.4,0.9-2.2)$ \\
\hline \multicolumn{2}{|l|}{$6-7$} & $41 / 273(15.0,10.8-20.4)$ & $15 / 460(3.3,1.8-5.4)$ \\
\hline
\end{tabular}

Abbreviations: $\mathrm{Cl}$ = confidence interval; DWI = diffusion-weighted MRI. comes at 7 days, categorized by infarction status and ABCD2 score cutpoints of $0-3,4-5$, and $6-7$, for DWI and CT cohorts and all cohorts combined. These cutpoints are often used to identify patients at low, moderate, and high risk of early stroke.,

DISCUSSION The usefulness of a definition of a condition in clinical medicine depends on whether it informs clinicians and patients by reliably identifying groups with a specific prognosis or requirement for treatment. In this study, tissue-positive TIA corresponded to stroke with rapid and complete recovery according to the ASA definition. Our findings support the concept of this tissue-based definition of TIA and stroke and show that DWI is superior to $\mathrm{CT}$ on prognostic grounds.

The substantial difference in outcome between these groups is clinically relevant and should influence management decisions involving the urgency of treatment such as triage and admission to the hospital. For DWI cohorts, a 7-day stroke risk of 7.1\% in tissue-positive events probably necessitates hospital admission or at least some other form of emergency investigation and treatment, whereas a stroke rate of $0.4 \%$ at 7 days could represent a low enough risk for patients to be managed safely on an outpatient basis. This difference in outcome could also be exploited in the efficient design of clinical trials of secondary prevention by identifying subjects with a potential for higher rates of outcome events, thereby reducing the total numbers needed to recruit. Recent guidelines highlight the importance of management in specialist neurovascular units offering urgent treatment and investigations. ${ }^{4-6}$ Interestingly, when cohorts from these units only are considered, ${ }^{24-28}$ the observed rate of stroke at 7 days was $1.9 \%$, consistent with the benefits of urgent treatment observed in the EXPRESS and SOS-TIA studies. ${ }^{25,29}$

Of the 3,206 patients who underwent DWI, 884 (27.6\%) were tissue-positive and 2,322 (72.4\%) were tissue-negative. Rates of recurrent stroke at 7 days in these groups were $7.1 \%$ vs $0.4 \%$, respectively, an 18 -fold difference. In acute coronary syndromes (ACSs), troponin levels are considered to generate prognostic information by distinguishing between tissue-positive and tissue-negative events. However, in patients with non-ST elevation ACS, rates of recurrent myocardial infarction or death are 2- to 5 -fold different in those with elevated vs normal levels of troponin..$^{30,31}$ Moreover, studies of ACS have tended to use longer periods of follow-up and varying definitions of reinfarction, which may exaggerate differences in observed rates. This comparison with ACS underlines the predictive power and clinical usefulness of infarction on DWI. 
Although DWI was developed more than 20 years ago, ${ }^{32}$ its technology continues to advance. Improvements in magnetic field strength and spatial resolution with reductions in scan slice thickness are likely to improve sensitivity for infarction. ${ }^{33}$ Compared with follow-up brain imaging, the false-negative rate for DWI is appreciable, with poorer detection of lacunar infarcts in the brainstem and internal capsule areas. ${ }^{34}$ If the small group of patients without infarction on DWI who had early strokes represents those with false-negative imaging, then prognostication is likely to improve as DWI becomes more sensitive. Moreover, our study used a blunt definition of the presence of any acute infarct, whether correlating or inappropriate to the presenting symptoms, which may have diminished prognostic power. Similarly, we did not distinguish some other factors that may have yielded further prognostic information such as vascular territory, region (cortical vs subcortical), age, or multiplicity of infarcts. ${ }^{35}$

Studies of the prognostic yield of plain CT scanning after TIA have yielded conflicting results. However, studies have tended to recruit subjects in the subacute phase, reported longer-term vascular outcomes and survival, and analyzed other imaging abnormalities such as leukoaraiosis in addition to infarction. ${ }^{36}$ To our knowledge, there have only been 2 published studies in the acute phase of TIA specifically addressing the predictive power of infarction on CT imaging for early stroke recurrence. ${ }^{19,20}$ Both reported a significantly higher rate of recurrent stroke in tissue-positive cases. Although we used a pragmatic definition of acute or old infarction in the current study because of the uncertainty in reliably determining infarct age on CT, those with tissuepositive and tissue-negative events were still found to have different outcomes (recurrent stroke rate at 7 days of $12.8 \%$ vs $3.0 \%$ ). CT is less sensitive for acute ischemia than DWI, but infarction on CT could be a marker of particular stroke etiologies such as large artery disease or cardioembolic stroke, possibly explaining predictive value in the acute phase. Alternatively, (silent) infarction on CT is a marker for vascular disease elsewhere or other vascular risk factors, ${ }^{36}$ but this association is more likely to explain outcomes in the longer term. We did not find a significant difference in predictive power of CT as measured by AUC in the $0-7$ vs $8-90$ day periods, although our sample was not powered to detect such a difference.

In addition to reduced sensitivity for ischemia, CT also has the drawback of radiation exposure and therefore is not recommended for TIA when MRI is available and not contraindicated. However, our results show that, when MRI is unavailable, contrain- dicated, or not tolerated, CT can yield useful prognostic information. Further prognostication may be possible using newer CT techniques such as CT angiography and perfusion, but their role is currently uncertain.

Although the presence of infarction is the major determinant of early stroke, we have found that the $\mathrm{ABCD} 2$ score has predictive value in the acute phase in both tissue-positive and tissue-negative patients, identifying individuals at higher and lower risk within both these groups. Some authors have claimed that the predictive power of the ABCD2 score is explained mainly by its diagnostic function, by discriminating between those with genuine TIA at high risk of further vascular events and other nonneurovascular diagnoses. The score has been found to distinguish between these groups. ${ }^{37,38}$ However, the finding that the ABCD2 score is predictive in TIA patients with infarction shows that the score cannot work by diagnostic discrimination alone. We argue that the score remains clinically useful, particularly when applied to tissue-positive patients. In those with DWI tissue-positive events, the observed 7 -day stroke rate was $7.1 \%$ overall but was $1.8 \%$, $7.5 \%$, and $12.5 \%$ in those with ABCD2 scores of $0-3,4-5$, and $6-7$, respectively (ABCD2 cutpoints commonly used to identify low-, intermediate-, and high-risk groups) (table 3). A similar degree of risk stratification was observed in those with CT tissuepositive events.

Table 3 also shows that recurrent stroke rates are comparable in tissue-negative events with high $\mathrm{ABCD} 2$ scores and tissue-positive events with low ABCD2 scores. Indeed we found overlaps in stroke rates in tissue-negative events with high clinical risk scores and tissue-positive events with low clinical risk scores at both 7 and 90 days in CT cohorts and at 90 days in DWI cohorts. These findings show that transient neurologic events represent a continuous spectrum of risk and support the use of a combined approach to prognostication, using both clinical and imaging information. ${ }^{7,8}$ The association between infarction and risk in the longer term has not been addressed in large studies.

Although we believe our findings are valid, we acknowledge some shortcomings. There was a considerable difference in outcomes observed between cohorts using DWI compared with those using CT. Outcomes in observational studies of TIA depend on the health care setting because of treatment effect and referral bias. ${ }^{1} \mathrm{CT}$ tended to be used in ED- and population-based cohorts, and DWI was used in cohorts from specialist units, so it is likely that the difference in observed stroke rates between CT and DWI cohorts is partly explained by study methodol- 
ogy. If our results are to be generalized, they should be calibrated according to the health care setting. Scans were interpreted by individual centers, and there was no central adjudication, potentially leading to less reliability in interpretation but reflecting clinical reality. Our findings are based on patients with time-defined TIA, who, by definition, had transient symptoms that resolved within 24 hours. Although we have subcategorized these as tissue-positive and tissue-negative, our findings cannot be generalized to all tissue-defined stroke. Among those with a neurologic deficit lasting longer than 24 hours, the risk of subsequent stroke varies, with particularly high risk, comparable to that of time-defined TIA, observed in those with nondisabling symptoms and lower risk in those with major or disabling deficits. ${ }^{39,40}$ It has been proposed that a new syndrome-transient symptoms with infarction - should be recognized because of the differing prognosis between those with transient symptoms with and without infarction and those with a permanent deficit. ${ }^{15}$

In conclusion, we have found that subcategorization of patients with TIA as defined by time-based criteria into tissue-positive and tissue-negative groups yields helpful prognostic information, especially when brain infarction is found on DWI. The ABCD2 score further refines risk in both tissuepositive and tissue-negative groups.

\section{AUTHOR CONTRIBUTIONS}

All authors ascertained patients and contributed data. M.F.G. and P.M.R. devised the study. M.F.G. and P.M.R. wrote the manuscript. All authors reviewed and approved the manuscript.

\section{DISCLOSURE}

Dr. Giles has received funding for travel and speaker honoraria from Boehringer Ingelheim and has received research support from National Institute of Health Research. Dr. Albers serves on a scientific advisory board for Lundbeck Inc.; has received funding for travel or speaker honoraria from Genentech, Inc.; serves on the editorial board of Stroke; serves as a consultant for Bristol-Myers Squibb, Merck Serono, Arbor Vita Corporation, AstraZeneca, and Mitsubishi Tanabe Pharma Corporation; receives research support from the NIH; and has served as an expert witness in medico-legal cases. Dr. Amarenco serves on scientific advisory boards for and has received funding for travel and speaker honoraria from BristolMyers Squibb, Pfizer Inc, Merck Serono, AstraZeneca, sanofi-aventis, and Boehringer Ingelheim; serves as Associate Editor, Europe for Stroke; and receives research support from sanofi-aventis, Bristol-Myers Squibb, Merck Serono, AstraZeneca, and PHRC. Dr. Arsava reports no disclosures. Dr. Asimos receives research support from Boehringer Ingelheim. Dr. Ay serves on the editorial boards of Stroke and Cerebrovascular Diseases and receives research support from the NIH. Dr. Calvet reports no disclosures. Dr. Coutts receives research support from Pfizer Inc, CIHR, Alberta-Innovates-Health Solutions, and a Heart and Stroke Foundation of Canada's Distinguished Clinician Scientist award, supported in partnership with the CIHR, Institute of Circulatory and Respiratory Health, and AstraZeneca. Dr. Cucchiara serves on a data safety monitoring board for Wyeth; has received speaker honoraria from Boehringer Ingelheim and diaDexus, Inc.; has received publishing royalties from UpToDate, Inc.; serves as a consultant for Ferrer, diaDexus, Inc., and iNova Pharmaceuticals; and receives research support from the NIH, the American Heart Association, and the American Stroke Association. Dr. Demchuk served on scientific advisory boards for Boehringer Ingelheim and Bayer Schering Pharma; has received funding for travel from sanofi-aventis; serves on the editorial boards of Journal of Neuroimaging, Stroke, and the International Journal of Stroke; has received speaker honoraria from Boehringer Ingelheim; receives research support from Novo Nordisk, the NIH/NINDS, and the CIHR; and owns stock in Calgary Scientific, Inc. Dr. Johnston is co-holder of patent re: the RNA panel to identify TIA and risk stratify and receives research support from sanofi-aventis, Strkyer Neurovascular, Boston Scientific, the NIH (NCRR, NINDS), Kaiser-Permanente, and AHA/ASA Bugher Award. Dr. Kelly has received research support to his institution from Pfizer Inc, Servier, and Bristol-Myers Squibb and has received research support from the Health Research Board of Ireland and the Irish Heart Foundation. Dr. Kim receives research support from the NIH (NCRR, NINDS), the American Heart Association, and the National Stroke Association. J. Labreuche and Dr. Lavallee report no disclosures. Dr. Mas serves on scientific advisory boards for AstraZeneca, Bayer Schering Pharma, Boehringer Ingelheim, sanofi-aventis/Bristol-Myers Squibb, Servier, and Takeda Pharmaceutical Company Limited; has received research support from Boehringer Ingelheim, sanofi-aventis, and Servier; and receives research support from sanofi-aventis, the French Ministry of Health, and INSERM Institut National Scientifique et de la Recherche Medicale. Dr. Merwick has received research support from Pfizer Inc, Lundbeck Inc., and Boehringer Ingelheim and receives salary support from the Health Research Board of Ireland. Dr. Olivot reports no disclosures. Dr. Purroy received research support from the Ministerio de Sanidad y Consumo, Instituto de Salud Carlos III. Dr. Rosamond receives research support from the CDC and the NIH. Dr. Sciolla reports no disclosures. Prof. Rothwell serves on scientific advisory boards for Bayer Schering Pharma, Servier, Pfizer Inc, and Biotronic; has received funding for travel from sanofi-aventis, Servier, AstraZeneca, and Bayer Schering Pharma; and serves on the editorial boards of Lancet Neurology, Stroke, and Cerebrovascular Diseases and as Assistant Editor for the International Journal of Stroke.

Received November 4, 2010. Accepted in final form April 7, 2011.

\section{REFERENCES}

1. Giles MF, Rothwell PM. Risk of stroke early after transient ischaemic attack: a systematic review and meta-analysis. Lancet Neurol 2007;6:1063-1072.

2. Wu CM, McLaughlin K, Lorenzetti DL, et al. Early risk of stroke after transient ischemic attack: a systematic review and meta-analysis. Arch Intern Med 2007;167:24172422.

3. Johnston SC, Rothwell PM, Nguyen-Huynh MN, et al. Validation and refinement of scores to predict very early stroke risk after transient ischaemic attack. Lancet 2007; 369:283-292.

4. Department of Health. National Stroke Strategy. London: Crown; 2007.

5. National Stroke Foundation. Clinical Guidelines for Acute Stroke Management [online]. Melbourne, Australia: National Stroke Foundation; 2007. Available at: www.strokefoundation.com.au. Accessed September 14, 2010.

6. Stroke Foundation of New Zealand. New Zealand Guideline for the Assessment and Management of Transient Ischaemic Attack [online]. Wellington, New Zealand. Available at: www.stroke.org.nz. Accessed September 14, 2010.

7. Giles MF, Albers GW, Amarenco P, et al. Addition of brain infarction to the ABCD2 score (ABCD2-I): a collaborative analysis of unpublished data on 4574 patients. Stroke 2010;41:1907-1913.

8. Merwick A, Albers GW, Amarenco P, et al. Addition of brain and carotid imaging to the ABCD2 score to identify patients at early risk of stroke after transient ischaemic at- 
tack: a multicentre observational study. Lancet Neurol 2010;9:1060-1069.

9. Hatano S. Experience from a multicentre stroke register: a preliminary report. Bull World Health Org 1976;54:541553.

10. Advisory Council for the National Institute of Neurological and Communicative Disorders and Stroke II. Classification and outline of cerebrovascular diseases II. Stroke 1975;6:564-616.

11. Easton JD, Saver JL, Albers GW, et al. Definition and evaluation of transient ischemic attack: a scientific statement for healthcare professionals from the American Heart Association/American Stroke Association Stroke Council; Council on Cardiovascular Surgery and Anesthesia; Council on Cardiovascular Radiology and Intervention; Council on Cardiovascular Nursing; and the Interdisciplinary Council on Peripheral Vascular Disease Stroke 2009; 40: 2276-2293.

12. Albers GW, Caplan LR, Easton JD, et al. Transient ischemic attack: proposal for a new definition. N Engl J Med 2002;347:1713-1716.

13. Purroy F, Montaner J, Rovira A, et al. Higher risk of further vascular events among transient ischaemic attack patients with diffusion-weighted imaging acute lesions. Stroke 2004;35:2313-2319.

14. Coutts SB, Simon JE, Eliasziw M, et al. Triaging transient ischemic attack and minor stroke patients using acute magnetic resonance imaging. Ann Neurol 2005;57:848-854.

15. Ay H, Koroshetz WJ, Benner T, et al. Transient ischemic attack with infarction: a unique syndrome? Ann Neurol 2005;57:679-686.

16. Giles MF, Rothwell PM. Systematic review and pooled analysis of published and unpublished validations of the $\mathrm{ABCD}$ and $\mathrm{ABCD} 2$ transient ischemic attack risk scores. Stroke 2010;41:667-673.

17. Rothwell PM, Giles MF, Flossmann E, at al. A simple score $(\mathrm{ABCD})$ to identify individuals at high early risk of stroke after transient ischaemic attack. Lancet 2005;366: 29-36.

18. Sheehan OC, Kyne L, Kelly LA, et al. Population-based study of $\mathrm{ABCD} 2$ score, carotid stenosis, and atrial fibrillation for early stroke prediction after transient ischemic attack: the North Dublin TIA study. Stroke 2010;41: $844-850$

19. Sciolla R, Melis F, SINPAC Group. Rapid identification of high-risk transient ischemic attacks: prospective validation of the ABCD score. Stroke 2008;39:297-302.

20. Douglas VC, Johnston CM, Elkins J, et al. Head computed tomography findings predict short-term stroke risk after transient ischemic attack. Stroke 2003;34:28942898.

21. Coutts SB, Eliasziw M, Hill MD, et al. An improved scoring system for identifying patients at high early risk of stroke and functional impairment after an acute transient ischemic attack or minor stroke. Int J Stroke 2008;3:3-10.

22. Purroy F, Begué R, Quílez A, et al. The California, ABCD, and unified $\mathrm{ABCD} 2$ risk scores and the presence of acute ischemic lesions on diffusion-weighted imaging in TIA patients. Stroke 2009;40:2229-2232.

23. Asimos AW, Johnson AM, Rosamond WD, et al. A multicenter evaluation of the ABCD2 score's accuracy for predicting early ischemic stroke in admitted patients with transient ischemic attack. Ann Emerg Med 2010;55:201210 .
24. Cucchiara B, Messe S, MacKenzie L, et al. D-dimer, magnetic resonance imaging diffusion-weighted imaging, and $\mathrm{ABCD} 2$ score for transient ischemic attack risk stratification. J Stroke Cerebrovasc Dis 2009;18:367-373.

25. Lavallee PC, Meseguer E, Abboud H, et al. A transient ischaemic attack clinic with round-the-clock access (SOSTIA): feasibility and effects. Lancet Neurol 2007;6:953960.

26. Calvet D, Touze E, Oppenheim C, et al. DWI lesions and TIA etiology improve the prediction of stroke after TIA. Stroke 2009;40:187-192.

27. Ay H, Arsava EM, Johnston SC, et al. Clinical- and imaging-based prediction of stroke risk after transient ischemic attack: the CIP model. Stroke 2009;40:181-186.

28. Mlynash M, Olivot JM, Tong DC, at al. Yield of combined perfusion and diffusion MR imaging in hemispheric TIA. Neurology 2009;72:1127-1133.

29. Rothwell PM, Giles MF, Chandratheva A, et al. Effect of urgent treatment of transient ischaemic attack and minor stroke on early recurrent stroke (EXPRESS study): a prospective population-based sequential comparison. Lancet 2007;370:1432-1442.

30. Heidenreich PA, Alloggiamento T, Melsop K, et al. The prognostic value of troponin in patients with non-ST elevation acute coronary syndromes: a meta-analysis. J Am Coll Cardiol 2001;38:478-485.

31. Scirica BM. Acute coronary syndrome: emerging tools for diagnosis and risk assessment. J Am Coll Cardiol 2010;55: 1403-1415.

32. Moseley ME, Cohen Y, Kucharczyk J, et al. Diffusionweighted MR imaging of anisotropic water diffusion in cat central nervous system. Radiology 1990;176:439-445.

33. Benameur K, Bykowski JL, Luby M, Warach S, Latour LL. Higher prevalence of cortical lesions observed in patients with acute stroke using high-resolution diffusion-weighted imaging. AJNR Am J Neuroradiol 2006;27:1987-1989.

34. Ay H, Buonanno FS, Rordorf G, et al. Normal diffusionweighted MRI during stroke-like deficits. Neurology 1999;52:1784-1792.

35. Ay H, Gungor L, Arsava EM, et al. A score to predict early risk of recurrence after ischemic stroke. Neurology 2010; 74:128-135.

36. van Swieten JC, Kappelle LJ, Algra A, et al. Hypodensity of cerebral white matter in patients with transient ischaemic attack or minor stroke: influence on the rate of subsequent stroke: Dutch TIA Study Group. Ann Neurol 1992;32:177-183.

37. Josephson SA, Sidney S, Pham TN, Bernstein AL, Johnston SC. Higher ABCD2 score predicts patients most likely to have true transient ischemic attack. Stroke 2008; 39:3096-3098.

38. Quinn TJ, Cameron AC, Dawson J, Lees KR, Walters MR. ABCD2 scores and prediction of non-cerebrovascular diagnoses in an outpatient population: a case-control study. Stroke 2009;40:749-753.

39. Johnston SC, Leira EC, Hansen MD, Adams HP Jr. Early recovery after cerebral ischemia risk of subsequent neurological deterioration. Ann Neurol 2003;54:439-444.

40. Coutts SB, Hill MD, Campos CR, et al. Recurrent events in transient ischemic attack and minor stroke: what events are happening and to which patients? Stroke 2008;39: 2461-2466. 